\title{
Manual Operacional de Armamento Aéreo
}

El manual se enmarca en el ámbito de los niveles superiores en esta materia.

El estudio se encuentra contextualizado en la doctrina táctica con base en documentos similares emitidos por la Fuerza Aérea Colombiana, como por ejemplo el Manual Técnico de Armamento Aéreo, y otras fuentes mundiales que son autoridades en el tema.

En estos documentos se encuentran las diferentes directivas, boletines y órdenes permanentes emitidas por el Comando de la Fuerza Aérea, dónde se establece de qué for- rencia obligado para el desarrollo de futuras aplicaciones clasificadas en el nivel más específico de la doctrina? Para dar respuesta a la anterior pregunta se hace necesario replantear y documentar la doctrina táctica acerca de la utilización del armamento para ser más efectivos en el combate $y$ en el momento de operarlos. De ahí, que se realizó un estudio descriptivo que permitió la recopilación de la información para efectuar las descripciones de las características y tipos de armamento utilizados, el rendimiento y los diferentes programas para la toma de decisiones.

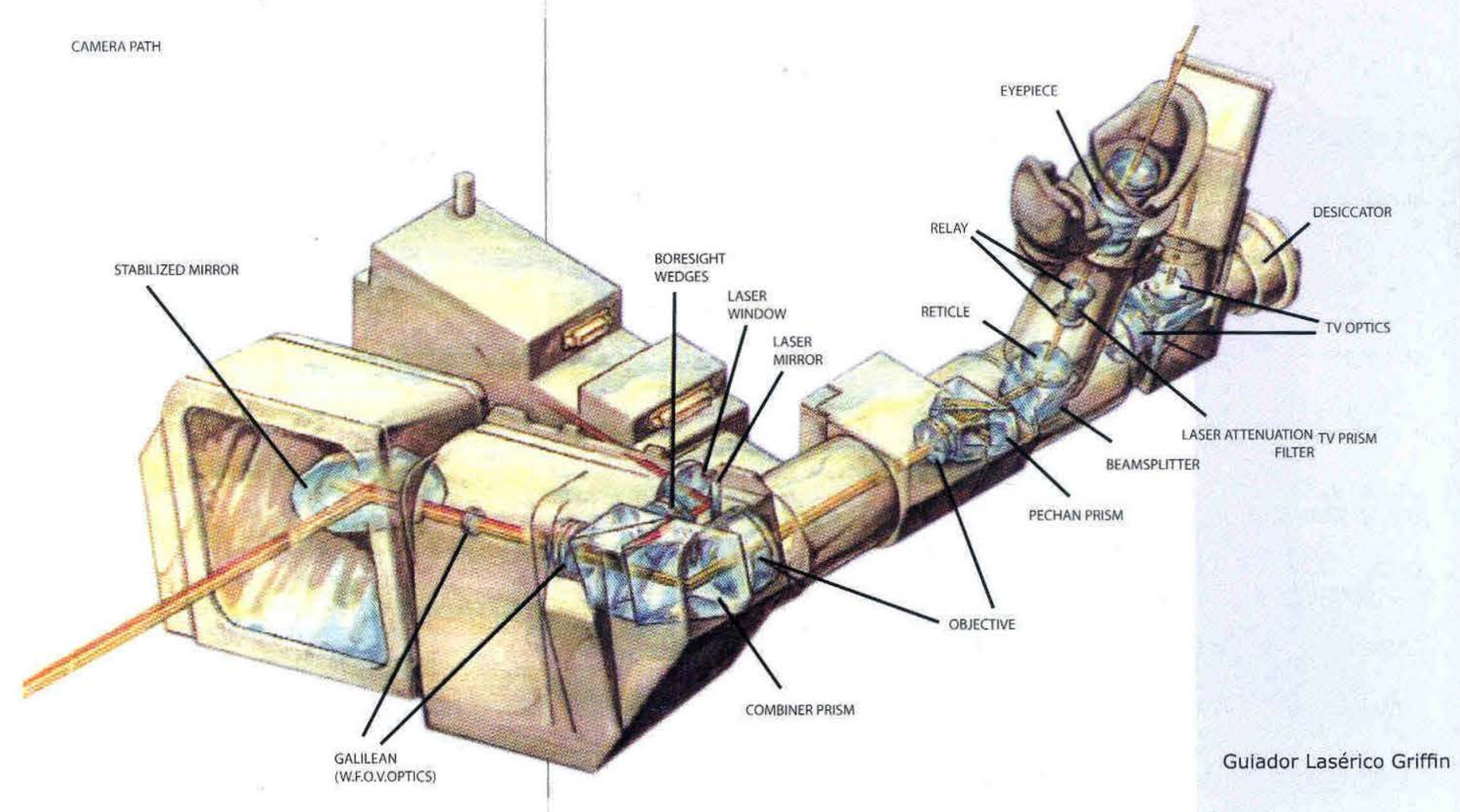

ma y en qué momento se utilizarán los medios aéreos y su respectivo armamento en las diferentes misiones. Entonces, ¿cuál debería ser el complemento de la doctrina básica y táctica, que se convierta en un punto de refe-
Así el contenido del manual presenta una historia del armamento en la Fuerza Aérea, un capítulo con las definiciones más utilizadas en el campo del armamento, la organización para el combate que tiene como ob- 


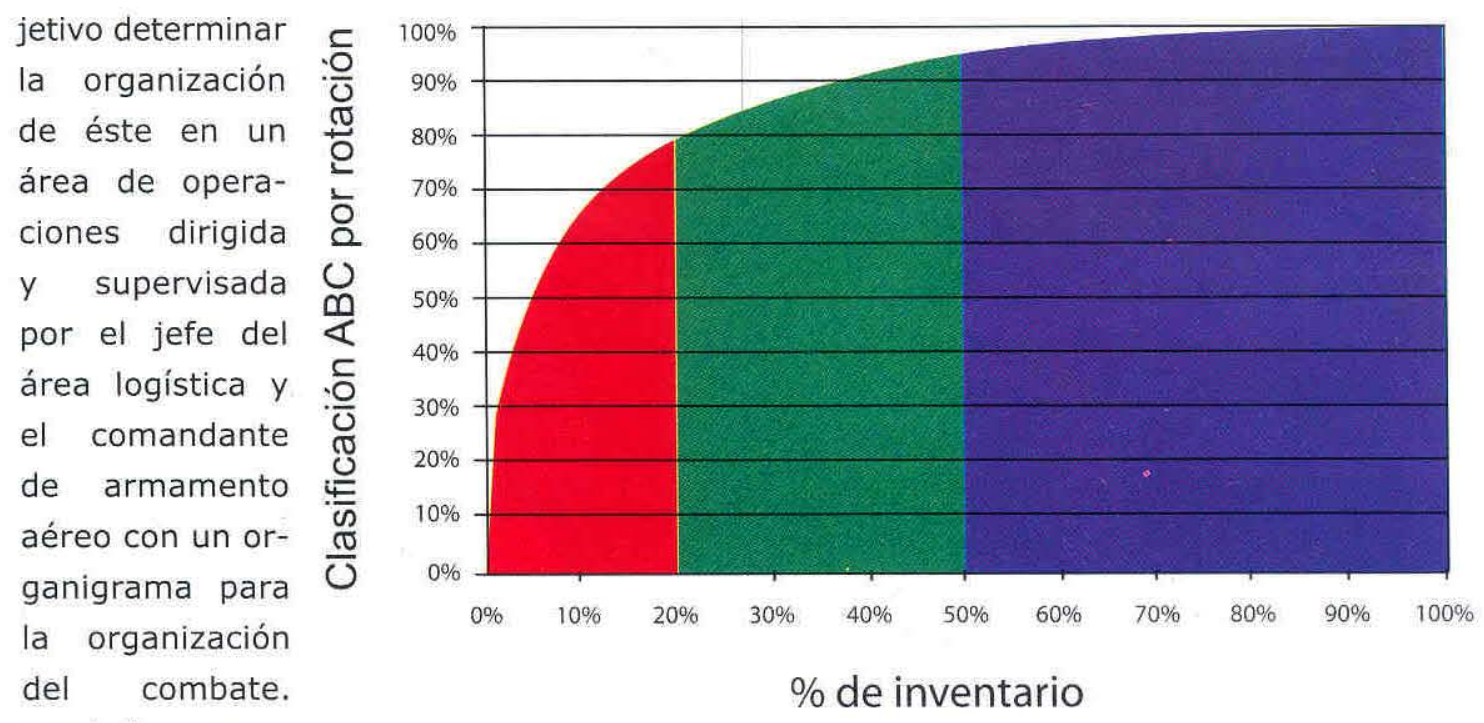

También se pre-

En el aparte de destrucción de objetivos sentan las normas de seguridad y entrenamiento para el personal de armamento. Entre ellas se encuentran normas de seguridad y manipulación del material de guerra y el entrenamiento del personal de arma-

\section{IDENTIFICACIÓN GENERAL DEL PROYECTO}

PROGRAMA

ESPECIALIZACIÓN EN LOGÍSTICA AERONÁUTICA

TÍTULO

MANUAL OPERACIONAL DE ARMAMENTO AÉREO

AUTORES Capitán JOSÉ LUIS CONDE BARBERY Capitán JUAN CARLOS RUEDA

CARTAGENA

Capitán GUILLERMO ZUÑIGA SANTANA

LÍNEA DE

INVESTIGACIÓN ARMAMENTOAÉREO

ÁREA

FUNCIONAL LOGÍSTICA AERONÁUTICA

GESTOR JEFEDE PLANEACIÓN-JOL

AÑO

2003 mento aéreo.

En la segun-

da parte se encuentra el capitulo uno que establece el sistema de armas entre los que está el sistema de armamento compuesto por el sistema de entrega de armas. La información se complementa con gráficos, figuras y dibujos de los diferentes tipos de armas. Igualmente, se describen los daños de las municiones y explosivos con los efectos destructivos según la clasificación de las municiones utilizadas según el objetivo. se presentan las generalidades y su correspondiente clasificación como los objetivos en el mar con tablas y cuadros; los objetivos en tierra igualmente con datos, tablas y gráficas.

La tercera parte del manual se refiere a los helicópteros donde presenta los siguientes modelos: H-500, AB212, AH60L. De acuerdo con este parámetro describe las características, las normas que deben conocer las tripulaciones y las reglas de seguridad. En el capitulo de aviones los clasifica según los siguientes modelos: M-5, K-FIR, A-37, AT-27, AC-47, TOV-10, que se utilizan para el comandante con el planeamiento de una operación de tal forma que hace la referencia de las características, las capacidades, configuraciones, los sistemas y tipos de armas. Asímismo, presenta la lista de chequeo del comandante para el planeamiento de una operación, el uso del armamento aéreo y las configuraciones típicas de los escuadrones de aeronaves según el modelo.

Con el compendio de este manual se establece una doctrina táctica, se estandariza la utilización de las aeronaves de acuerdo con el tipo de armamento y se tiene una panorámica completa con sus respectivos impactos. 